\title{
Remote mine sensing technology by using IR Images
}

\author{
Nobuhiro Shimoi ${ }^{1, *}$, Yoshihiro Takita ${ }^{2}$ \\ ${ }^{1}$ Department of Machine Intelligence and Systems Engineering, Akita Prefectural University, Yurihoujo, 015-0055 Japan \\ ${ }^{2}$ Department of Computer Science, National Defence Academy, Yokosuka, 293-8686 Japan
}

\section{Email address:}

shimoi@akita-pu.ac.jp (N. Shimoi), takita@nda.ac.jp (Y. Takita)

\section{To cite this article}

Nobuhiro Shimoi, Yoshihiro Takita. Remote Mine Sensing Technology by Using IR Images, American Journal of Remote Sensing. Vol. 1, No. 2, 2013, pp. 33-37. doi: 10.11648/j.ajrs.20130102.13

\begin{abstract}
This paper proposes an IR camera system that performs the task of removing mines for humanitarian purposes. Because of the high risks involved, it is necessary to conduct mine detection from the most remote endeavoring. By making use of infrared ray (IR) cameras, scattered mines can be detected from remote locations. In the case of mines buried in the ground, detection is possible if the peripheral temperature difference is large enough between the ground and mine weapon. Tests with trial mines were used to study the detection characteristics of IR cameras for images and various technologies for collecting and processing image data in real time for optimum mine detection.
\end{abstract}

Keywords: Mine, Remote Sensing, IR Images

\section{Introduction}

Despite the end of the Cold War, as many as 80 million anti-personnel mines are left buried today and they are still killing or injuring many people all over the world [1] . These mines maim or injure approximately 3000 individuals each year. They are a particularly acute problem in developing countries and nations already economically hard hit by war. The problem of unexploded mines has become a serious international issue with many people striving to find a solution. Several international conferences on mine detection and removal technology are held each year [2][3]. However, regional wars and conflicts have broken out one after another and new mines are being buried to repeat these tragedies. Land mine weapons buried several centimeters under the ground are difficult to detect and even when detected successfully, it is difficult to dispose of them. Since mines are designed to kill or wound people, the technologies for detection and disposal must be highly reliable. Figs.1, 2 shows the exterior appearance of the 72A plastic mine and the P-25 trip wire (tension) initiated type mine. Among the types of sensors currently used for detecting mines buried underground include radar types (e.g., microwave pulse sensors, FM-CW and $\mathrm{CW}$ sensors) and magnetic types. However, since these sensors are housed in caster or tire type frames, vibrations transmitted from the ground surface during sensing and operation of these devices negatively influence their detection characteristics.

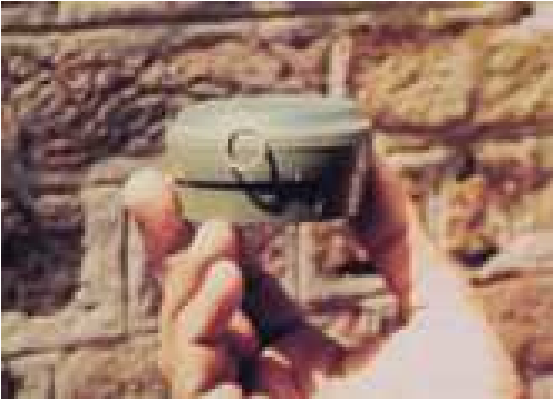

Figure 1. $72 A$ land mine.

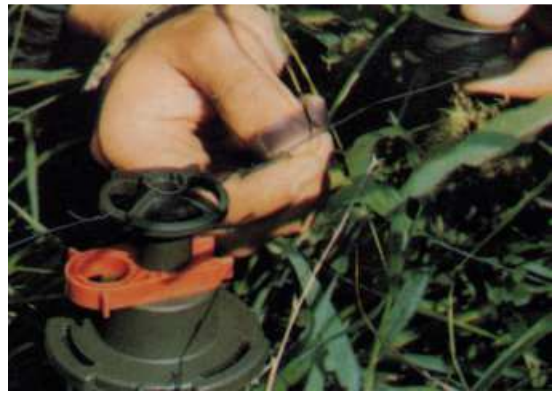

Figure 2. P25 Anti-personnel mines trip wire.

Fig. 3 shows mine detection conducted with contact probes, but this method of detection is very dangerous $[4][5][8]$. As one of the world's advanced nations in sensor technology, Japan should promote surveys and studies on how to detect these mine weapons safely by using its ad- 
vanced smart sensing technologies.

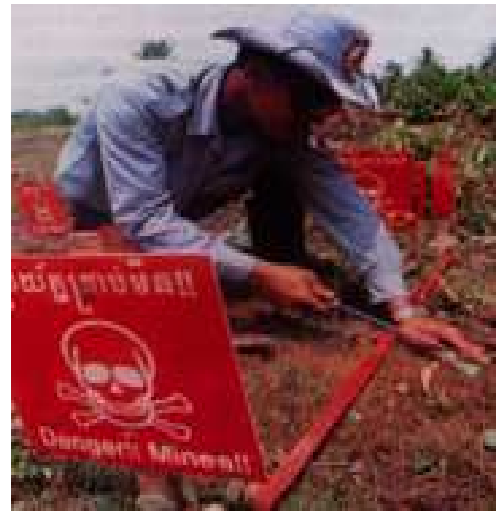

(a) Mine detection using contact probes

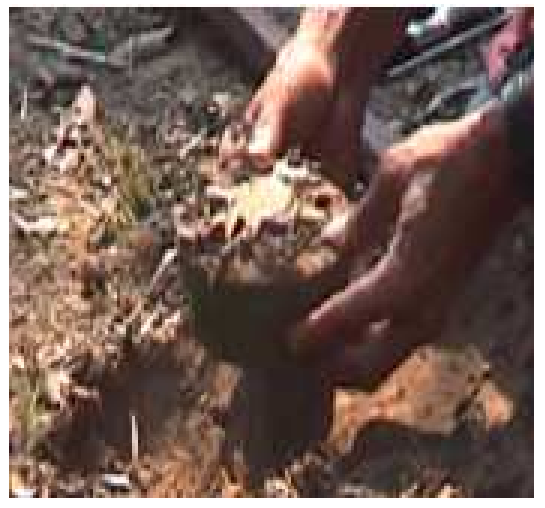

(b) PMN-2 Antipersonnel mine

Figure 3. The most effective detecting methods currently depend on human workers.

Because of the danger involved, we propose the use of smart sensing methods for detecting land mine weapons. Specifically, by using infrared ray IR cameras, the work of detecting scattered mines can be done from a safe remote location. When mines are buried in the ground, it is possible to detect them if the peripheral temperature differences between the ground and mine are large enough to sense. The authors have studied how to develop high level instrumentation technologies for mine detection. Mine detection and disposal technologies will be improved by using measuring equipment mounted on IR cameras and this will lead to active control remote sensing [5][6].

\section{Configuration and Theory of the IR- Camera Image System}

\subsection{Configuration}

Fig. 4 shows the basic configuration of the land mine detecting system using IR cameras. The results of measurements from the IR camera and processing signals are sent at the same time to the information processing segment. after the information is processed, the picture information is sent to an exclusive picture indicator and the operator can de- termine the position of mines at this time. [6][7]

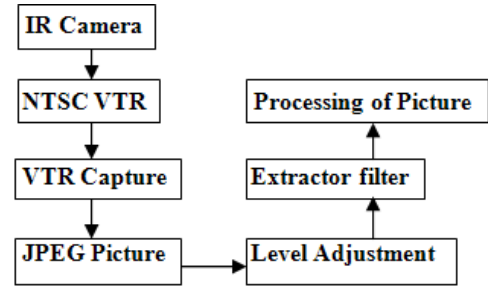

Figure 4. Configuration of the land mine detection system using an IR camera.

\subsection{Theory of the Measurement Principle of the IR Cam- era.}

Generally, a cold object emits energy by infrared radiation. Formula (1) shows the plank radiation low, and formula (2) shows the Boltzmann low for energy radiation. [8]

$$
W \lambda b=\frac{2 \pi h c^{2}}{\lambda^{5}\{\exp (h c / \lambda k t)-1\}} \times 10^{-5}\left[\mathrm{Watts} / \mathrm{m}^{2} \cdot \mu \mathrm{m}\right]
$$

Where,

$\mathrm{W} \lambda \mathrm{b}:$ the black body radiation spectroscope ( $\lambda$ wave)

$\mathrm{c}:$ the velocity of light $\left(=3 \times 10^{3} \mathrm{~m} / \mathrm{sec}\right)$

$\mathrm{h}:$ Plank's constant $\left(=6.6 \times 10^{-34} \mathrm{~J} . \mathrm{sec}\right)$

$\mathrm{k}$ : the Boltzmann constant $\left(=1.4 \times 10^{-23} \mathrm{~J} / \mathrm{K}\right)$

$\mathrm{t}:$ the absolute temperature of blackbody $(\mathrm{K})$

$\lambda:$ the wavelength $(\mathrm{m})$

$$
W b=\sigma t^{4} \quad\left[\text { Watts } / \mathrm{m}^{2}\right]
$$

Where,

$\mathrm{Wb}$ : the integral of black body radiation from

: Plank's formula from wavelength 0 to $\infty$

$\alpha$ : the Boltzmann constant $(=5.7 \times 10-8 \mathrm{Watts} / \mathrm{m} 2)$

$\mathrm{t}$ : the absolute temperature of blackbody $(\mathrm{K})$

From these equations, we find that all energies increase linearly with temperature, but wavelength representing the peak value of brightness becomes shorter.

The only factor deciding the temperature of radiation is the black body temperature. It exists in a very wide spectrum of frequency and it has a maximum value result. For instance, for room temperature $20\left({ }^{\circ} \mathrm{C}\right)($ Circa $300 \mathrm{~K})$ the energy distribution has a peak value at approximately $10(\mu \mathrm{m})$. Also, when we consider the penetration of wavelengths through the atmosphere, the passing zones of $3 \sim 5(\mu \mathrm{m})$ and $8 \sim$ $12(\mu \mathrm{m})$ are less attenuated by the atmosphere and can be considered suitable frequency zones for short-distance infrared rays. However, when these two frequencies are compared, the $8 \sim 12(\mu \mathrm{m})$ zone is more promising for mine detecting Sensors than the $3 \sim 5(\mu \mathrm{m})$ zone for reading measurements near the peak value at room temperature.

\section{Experimentation Methods}

Fig. 5 shows the experimental configuration. On the day of experimentation, the weather conditions were moderate with a temperature of $32\left({ }^{\circ} \mathrm{C}\right)$.Fig. 5 (a) shows the mock 
mines were buried for one day and night in the sand and measurements began at 9:00 a.m. By using rain equipment, 5 liters of cold water with ice $4\left({ }^{\circ} \mathrm{C}\right)$ were sprinkled evenly on the ground surface of the area to be measured. Immediately after this 15 minutes of measurements were taken. In this time, image data was recorded by a $8 \sim 12(\mu \mathrm{m})$ zone infrared camera (IR -U300M1) and a visual VTR camera to show the changing conditions. Fig.5 (b) shows thermocouples measured the change in temperature of the ground surface in the proximity of the buried mock mines. The composition of the mines buried were:(1) $90 \times 45 \mathrm{~mm}$ plastic ingot types,(2) $70 \times 45 \mathrm{~mm}$ plastic ingot types, (3) $60 \times 120 \mathrm{~mm}$ steel cylinders (containing $8 \mathrm{~mm} \times 150$ steel bale and $180 \mathrm{~g}$ clay), buried at $2(\mathrm{~cm})$ and $1(\mathrm{~cm})$ depths. In order to evaluate the detection images, we constructed a wooden frame with a copper wire grid spaced $10(\mathrm{~cm})$ apart to verify the location of the buried mine targets.

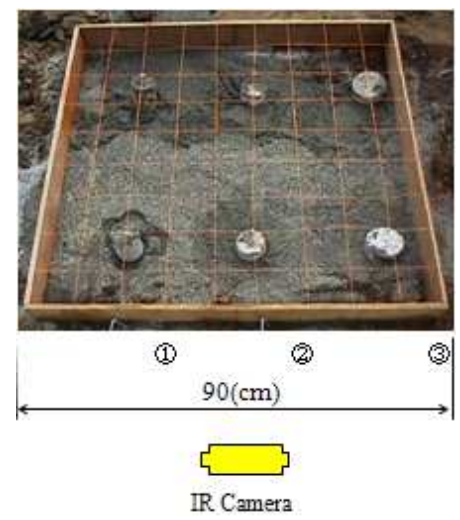

(a) Configuration of mock mine

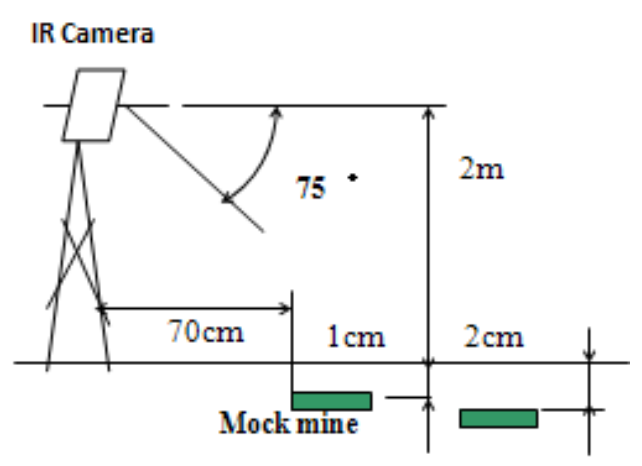

(b) Configuration of IR Camera

Figure 5. Experimental configuration.

\subsection{The Problem of Mine Detection Using Camera Image}

Almost all of the buried objects in this study are cylindrical type. Because of the effects of stones in the soil, it is difficult to efficiently detect the buried mines based on a simple binary processing using threshold values.

In addition, since ground temperature varies by region, we have to adjust the lamination level of the IR camera.

We already know that it is possible to detect buried mines based on radiated heat when the peripheral tempera- ture differences between the ground and mine object are large enough to sense. However, there is a problem because the reverse phenomenon, in which the temperature of the ground begins to rise after the ground surface is cooled, occurs in a very short time.

Hence, when IR camera images taken in the region outside the buried targets, a real time method is required to process pictures before and after the reverse phenomenon.

\subsection{The Detection Process}

(1) We imitated the actual survey situation as much as possible.

(2) We conducted tests outdoors in fair weather.

(3) We installed the IR camera $0.7 \mathrm{~m}$ away from the detection area.

\section{Overall Evaluation of the System}

Fig. 6 shows the two-dimensional temperature images of the mock mines taken by the infrared camera at select intervals just after cooling the ground using rain equipment. The coolant was sprinkled evenly over the ground surface where the mock mines were buried. For mines buried near the ground surface $(1 \mathrm{~cm}$ depth), the images taken after the 3 minutes mark appeared the most clearly. After 7 minutes, the image becomes indistinct and after 10 minutes, it is no longer possible to distinguish the mine target images.

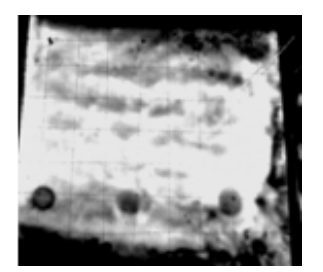

(a) After 3 minutes

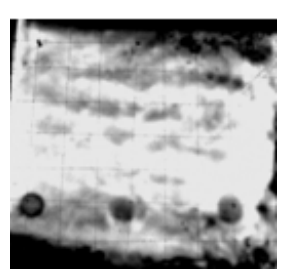

(b)After 7 minutes

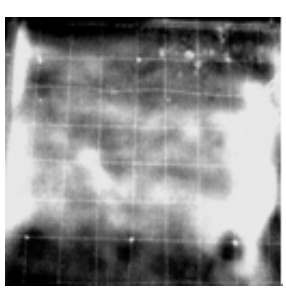

(c)After 10 minutes

Figure 6. Images from IR cameras.

This corresponds to measurement results shown in Fig 7. This result agrees with the theory that good mine location 
readings can be taken when the temperature gradient of the targets and the surrounding ground is large. Also, for targets buried at $2(\mathrm{~cm})$ depths, we could vaguely recognize the shape of mines from measurements taken at the $10 \mathrm{mi}-$ nutes mark when the temperature difference was the greatest. The reason why the result is not sufficiently good is that compared to targets buried at $1 \mathrm{~cm}$. depths, no sudden temperature changes could be detected from the thermometry results. From these results, we used the following image processing techniques to try to enhance the mine detection information.

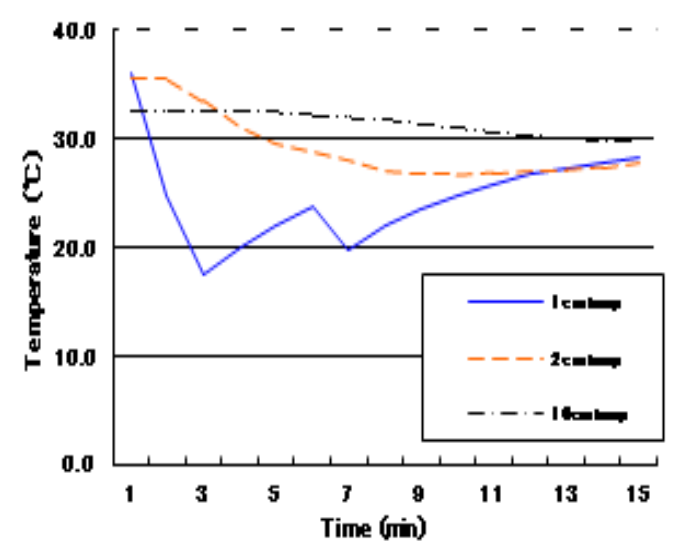

Figure7. Relationship between measuring time elapsed and underground mock mine temperatures.

Fig. 8 shows, in order to examine the mine regions in this study, images from the IR camera are recorded at a rate of 1 image frame per second and then input to the image processing system. The test image photographs were created under the following conditions. The picture (a) shows, the mine detection image from the IR camera (7 minutes elapsed). The images from the IR camera are converted into $768 \times 600$ pixel gray scaled pictures of 256 tones by the frame grabber hardware. Then, the horizontal width, vertical width and grayscale depth are recorded as $H w(=768), V w(=600)$ and $G d(=256)$ respectively.

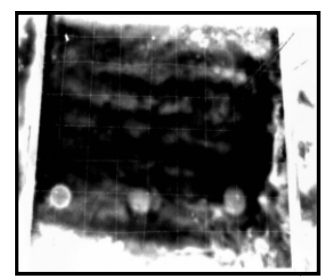

(a) Original picture

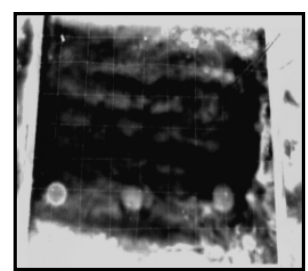

(b) Brightness level control

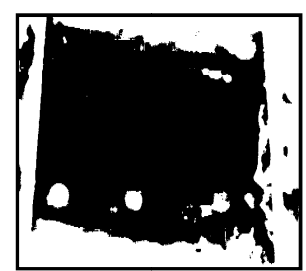

(c) Binary picture processing

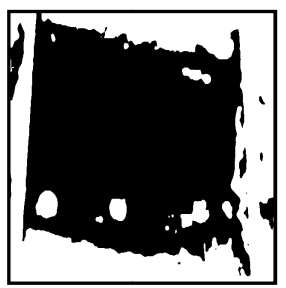

(d) Processing of crossover area

Figure 8. Images from IR cameras.

The picture (b) Brightness level control shows, the result of the luminance histogram cut by approximately $5 \%$ for high and low intensity. The picture (c) is the binary image of the result using 128 values for the luminance level. The picture (d) shows the result of using regional division processing for a 2-pixel radius Gaussian filter and then creating a binary image of it with 64 levels of luminance. By examining these results, we can correctly identify the location of six buried mine targets where the image displays white spots.

Fig.9 shows, the configuration diagram of the proposed detection processing system. The processing is composed of four parts, (A) A frame memory group for recording the time elapsed images, (B)Time difference image processing, (C) Mask generation and shading removal, and (D) Division of regions and labeling process.

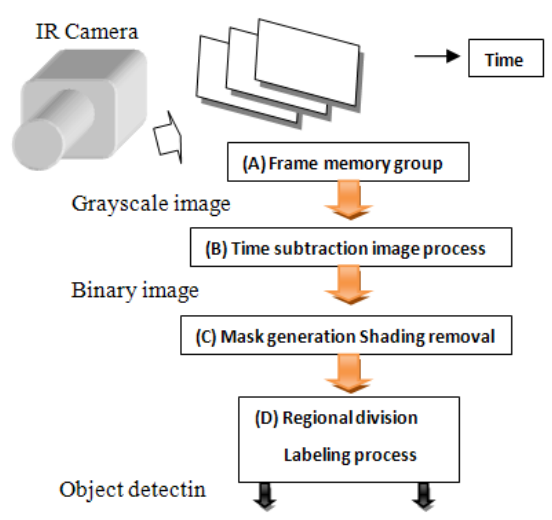

Figure 9. Configuration diagram of detection processing system.

Judging from these results, we can identify the location of 3 buried mock mine targets where the image displays white spots. In addition, by studying image processing technology, we can confirm the possibility of detecting mine targets buried at depths where normal recognition techniques have difficulties producing results. From the results of our work, the greatest merit of our active detec- 
tion system using cooling water and infrared cameras is that operators can perform detection remotely, and thus more safely than with present metal detectors and Ground Penetrating Rader sensors.

\section{Conclusion}

Furthermore, by employing more advanced methods of image processing technology, we have the possibility of detecting mine targets buried at depths where normal recognition techniques have difficulties producing results. The greatest merit of our active detection system using cooling water and infrared cameras is that operators can perform detection remotely, and thus more safely, than with present metal detectors and radar sensors. From the standpoint of detection capacity, the results indicate that our system serves as an effective detector for buried land mines. For the tests conducted in this work, we employed standard image processing techniques using infrared cameras on the market. In the future, we will study distance measurement technology and image processing technology for enhancing our mine detection system. We will also need to include in our team a specialist on chemical systems for the work of studying the permeability of cooling water to improve the effects of cooling.

As one means of overcoming problems concerning lethal land mine weapons, I proposed in this work the development of a mine detection system and demonstrated its potential. This work serves as a stepping stone for the development of mine removal technology for peaceful purposes. And then, as one of the world's advanced nations in sensor technology, Japan should promote surveys and studies that will help the work of detecting land mine weapons safely by using its advanced remote sensing technologies. It is our hope that our small breakthroughs in mining research for humanitarian purposes will help many researchers trying to find a way to save the people suffering from the attacks of mine weapons.

\section{Acknowledgements}

We would like to express our thanks to Mr. Osako for his assistance and cooperation during the outdoor experiments.

\section{References}

[1] Katuhisa Furuta, Kenzou Nonami, Nobuhiro Shimoi,et. al,: The study of humanitarian mine detecting and demining technology, Science Council of Japan, pp. 1-38 (2000).

[2] JCBL(NGO), Land mine monitor report: Japan Land Mine Ban Campaign, pp. 3-40 (1999).

[3] Nobuhiro Shimoi, The Subject NGO of the technology for mine detecting: JSME 99, D\&D, Vol. B99-7, pp. 277-280.

[4] Y.Takita, N. Shimoi, Development of Wheeled Mobil Robot Octal Wheel Realized Climbing Up and Down Stairs, Proceedings of 2004 IEEE/RSJ International Conference on Intelligent Robots and Systems, pp2440-2445(2004).

[5] N. Shimoi, K. Nonami, Mine detecting technology using IR camera, CICE, No. 42, pp. 34-36 (1999).

[6] N. Shimoi, S. Koga, K. Itoh, et. al.: "Vibration reduction study with air-cushion” , CICE, Vol. 33, No. 5, pp. 337-343 (1997).

[7] N. Shimoi, Q. Huang, H. Uchida, D. Komizo, K. Nonami: "The smart sensing for mine detection using IR camera" , JSME ROBOMEC’2000, pp. 93-94(2000).

[8] AGEMA In frat systems, "Primer of Infrared technology", Nacc,pp. 18-126 (1986).

[9] N. Shimoi : "The Technology of Personnel Mine Detecting for Humanitarian De-mining", SICE Vol. 37, No. 6, pp. 577-583 (2001).

[10] N.Shimoi, “Technology for detecting and clearing and mines”, Morikita Syuppan,pp48-126(2002). 